\title{
The Implementation of Combined Roughness and Reflected Model (CRRM) in Tsunami Run-up Simulation through Coastal Vegetation
}

\author{
Benazir \\ Doctoral Student at Department of Civil and Environmental Engineering, Universitas Gadjah Mada, Yogyakarta, INDONESIA \\ benazir_27iska@yahoo.com \\ Radianta Triatmadja \\ Department of Civil and Environmental Engineering, Universitas Gadjah Mada, Yogyakarta, INDONESIA \\ radianta@ugm.ac.id \\ Adam Pamudji Rahardjo \\ Department of Civil and Environmental Engineering, Universitas Gadjah Mada, Yogyakarta, INDONESIA \\ rahardjo.adam@ugm.ac.id \\ Nur Yuwono \\ Department of Civil and Environmental Engineering, Universitas Gadjah Mada, Yogyakarta, INDONESIA \\ nuryuwono@ugm.ac.id
}

\begin{abstract}
Hydraulics resistance is commonly used to simulate or replace drag and inertia forces due to vegetation when modeling tsunami run-up. A new numerical method was proposed which was named Combined Roughness and Reflected Model (CRRM). This method accommodates the reflection process of tsunami flow by tree surfaces. A series of experimental work was performed in laboratory to verify the numerical results. The physical process of laboratory work was discussed to explain the interaction between tsunami and vegetation models. The relation of some notable parameters was reviewed for both models. The physical model verified that the deviations between the physical and the numerical model were below 20\%. With such numerical method, more challenging forest layout such as zigzag arrangement can be studied more accurately. It is concluded that the zigzag arrangement of trees layout and higher density of trees were capable of reducing tsunami run-up on land significantly.
\end{abstract}

Keywords: model verification; physical; numerical; long wave; mitigation

\section{INTRODUCTION}

Coastal vegetation (Figure 1) is one of the alternatives used for tsunami mitigation. This alternative is quite good in terms of economics, especially for developing countries such as Indonesia. Another advantage of the implementation is that the vegetation can minimize local erosion due to wind wave attacks onshore and assist in producing sand dunes in front of coastal forests which ultimately serve as natural mitigation systems (Irtem et al., 2009). Several tsunami post-survey reports have proven that coastal vegetation has an important role as a natural protection against tsunamis as in Shuto (1987); Kathiresan \& Rajendran (2005); Dahdough-Guebas et al. (2005); Forbes \& Broadhead (2007); and Benazir et al. (2016). The studies were also confirmed by analytical and empirical research approaches. Based on a literature study, the effect of vegetation as a basic roughness has long been studied as by Chow (1959) who reported an increase of Manning roughness coefficient in vegetated open channels. A study of wave reduction in mangrove forests was done by Mazda et al. (1997) which discussed that wave reduction using mangrove forests depended on water depth, wave period, wave height, mangrove tree species, mangrove density, root diameter, and mangrove stem. Based on their study, a 6-year-old mangrove forest with a width of $1.5 \mathrm{~km}$ may dampen a $1 \mathrm{~m}$ wave height in open sea to merely 0.05 $\mathrm{m}$ at the beach.

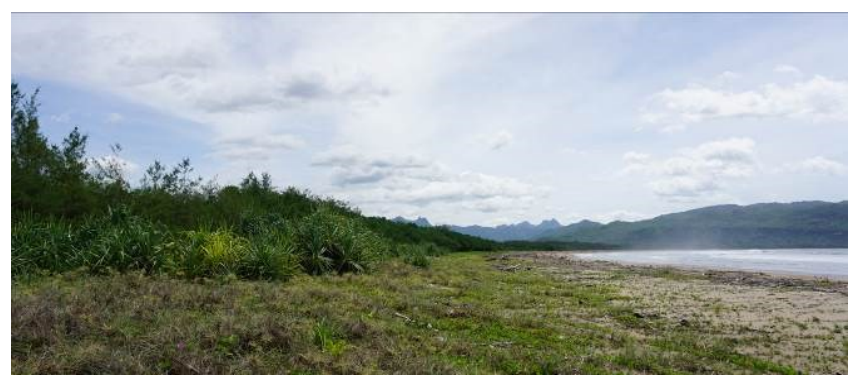

Figure 1. Coastal vegetation in Pacitan Bay, East Java

Hiraishi \& Harada (2003) proposed coastal forests as tsunami mitigation rather than with hard structures such as breakwater with a review of construction cost 
efficiency. Based on their 2D physical study, it revealed that tsunami reduction with coastal forests has a damping effect similar to a rubble mound. A study of the function of mangrove forests in reducing tsunami height during the 2004 Indian Ocean Tsunami was conducted by Kathiresan \& Rajendran (2005). Their assessment was based on tsunami victim's data in 18 small villages along the South Coast of India. According to their investigations, the damage caused by a tsunami attack depended on whether the area was protected by with coastal vegetation, the distance and elevation of the settlement location from the shore. Danielsen et al. (2005) also stated the effectiveness of mangrove forests in reducing tsunamis in Cuddalore, India. In addition, the age of the coastal forests is also pertinent to reduce tsunamis as indicated by the study conducted by Harada \& Kawata (2005). Furthermore, Harada \& Imamura (2005) evaluated the effect of hydrodynamics and damage prevention functions with coastal forests against tsunami. They concluded that an increase in the width of the coastal forest may not only reduce the inundation depth but also decrease the tsunami hydraulic velocity and force downstream of the coastal forest.

Nevertheless, the capability of coastal forests to withstand extreme tsunamis is still debatable in the discussion topics among researchers (Husrin \& Oumeraci, 2009). When the tsunami height reaches 4 $\mathrm{m}$, the function of the coastal forest is not applicable where trees will be uprooted and damaged (Shuto, 1987). This condition was proven by the 2004 Indian Ocean Tsunami in Aceh where most of the coastal forests were damaged by tsunami (EJF, 2006). Nowadays, the relation of vegetation parameters against tsunami was widely discussed. Practically, a numerical model is more efficient in conducting tsunami investigations through coastal forests. The effect of coastal forest density was studied by Hiraishi \& Harada (2003); Harada \& Kawata (2004); Huang et al. (2011); and Iimura \& Tanaka (2012) whilst the effect of the vegetation in term of dimension was studied by Teh et al. (2009) and Ohira et al. (2012). The effect of the forest may also be seen in term of the age of the forest trees as was studied by Harada \& Kawata (2005). In numerical model, the effect of coastal vegetation was generally represented by additional bottom roughness as well as by the addition of equation terms representing flow resistance (drag and inertia forces).

Benazir et al. (2017) introduced an alternative method of modeling the effect of coastal forest or similar barrier on tsunami run-up that is called Combined Roughness and Reflected Model (CRRM) where the performance of the method was compared with
Constant Roughness Model (CRM) and Equivalent Roughness Model (ERM) methods. They concluded that the CRRM method was able to accommodate the wave reflection process when interacted with trees. When small grid size is employed, the CRRM clearly produced more accurate results than its counterpart. This paper aims to further examine the performance of the CRRM method by performing verification using a physical model in the laboratory. Finally, the effect of density and planting layout of coastal vegetation were discussed.

\section{RESEARCH METHOD}

\subsection{Tsunami Model}

A numerical simulation of tsunami can be carried out using various models. In this research, the authors used the nonlinear shallow water equation. The main program was taken from Goto et al. (1997) and Imamura et al. (2006) which implemented secondorder explicit leap-frog finite difference scheme to discretize a set of Nonlinear Shallow Water Equation (NSWE). During the propagation of tsunami in the shallow water, the horizontal eddy turbulence terms may be neglected as they are negligible as compared to the bottom friction. The equations are written in Cartesian coordinate as (Imamura et al., 2006):

$\frac{\partial \eta}{\partial t}+\frac{\partial M}{\partial x}+\frac{\partial N}{\partial y}=0$

$\frac{\partial M}{\partial t}+\frac{\partial}{\partial x}\left(\frac{M^{2}}{D}\right)+\frac{\partial}{\partial y}\left(\frac{M N}{D}\right)+g D \frac{\partial \eta}{\partial x}+\frac{\tau_{x}}{\rho}=0$

$\frac{\partial M}{\partial t}+\frac{\partial}{\partial x}\left(\frac{M N}{D}\right)+\frac{\partial}{\partial y}\left(\frac{N^{2}}{D}\right)+g D \frac{\partial \eta}{\partial y}+\frac{\tau_{y}}{\rho}=0$

$D=h+\eta$ is the total water depth where $h$ is the still water depth and $\eta$ is the sea surface elevation. $M$ and $N$ are the water velocity fluxes in the $x$ and $y$ directions, respectively

$M=\int_{h}^{\eta} u d z=u(h+\eta)=u D$

$N=\int_{h}^{\eta} v d z=v(h+\eta)=v D$

Bottom friction in the $x$ and $y$ direction is respectively represented by terms $\tau_{x}$ and $\tau_{y}$, which is a function of friction coefficient $f$. This coefficient can be computed from Manning roughness $\left(n_{0}\right)$ by the following relationship

$n_{0}=\sqrt{\frac{f D^{1 / 3}}{2 g}} \rightarrow f=\frac{n_{0}{ }^{2} 2 g}{D^{1 / 3}}$

Eq. (3) indicates that the friction coefficient increases when the total water depth decreases. Manning 
roughness is usually chosen as a constant for a given condition of sea bottom, hence the bottom friction terms are expressed by

$\frac{\tau_{x}}{\rho}=\frac{1}{2} \frac{f}{D^{2}} M \sqrt{M^{2}+N^{2}}$

$\frac{\tau_{y}}{\rho}=\frac{1}{2} \frac{f}{D^{2}} N \sqrt{M^{2}+N^{2}}$

In this research, the bed slope of the sea and beach model was made of plywood, therefore the selected Manning coefficient $\left(n_{0}\right)$ was 0.012 .

\subsection{Combined Roughness and Reflected Model}

Generally, in numerical model simulation, the effect of coastal forests is presented by flow resistance in the absence of physical vegetation. The effects of coastal forests on tsunami propagation are reflections from tree trunks and roughness on the stem surfaces, branches, and leaves of the trees. In laboratory scale, the forest model can be made with certain materials which comprise stems, leaves, and roots. However, it is too complicated to model the trees realistically as above. The main objective of the forest model is to study the resistance of the tree against the tsunami. Therefore, stems and leaves may be simplified and accommodated within the tree's trunk. Thuy et al. (2009) and Maza et al. (2015) represented coastal forest models using vertical cylinder pillars as trees in the forest in the absence of leaves and roots using physical and numerical model respectively. Other than simulating forest effect on tsunami, Fernando et al. (2008) also carried out physical modeling using vertical cylindrical pillars to represent a porous barrier such as coral reefs.

Another alternative is to model the influence of coastal forest, using tree trunks as hypothetical column to model the whole trees (including branch and canopy). The branches and leaves effects are accommodated by the hypothetical column model whereas the bottom roughness value is used to simulate land use roughness coefficient i.e. $n_{0}$ (not for coastal forest). This method is called Combined Roughness and Reflected Model hereinafter referred to as CRRM method. The structural selection of a tree model in the form of a square column was determined as follows. First, based on the findings from the field survey that the geometries of the trees are not necessarily cylinders. However, they are almost cylinders and some even tend to an incomplete square as in Figure 2. Second, the forest height was higher than or equal to tsunami depth. As each hypothetical column represent one tree, the consequence is that the time step should be small and the computation time become long to meet the stability requirement.
The difference between this proposed method and ERM were in the existence of the tree model. In this method, the existing model was integrated with the ground surface, while in ERM is represented by the flow resistance as an equivalent roughness. Benazir et al. (2017) pointed out that the CRRM method changed the flow direction due to the existence the tree. In the ERM method, the flow was reduced when it passed through the coastal forest due to the effect of equivalent roughness.

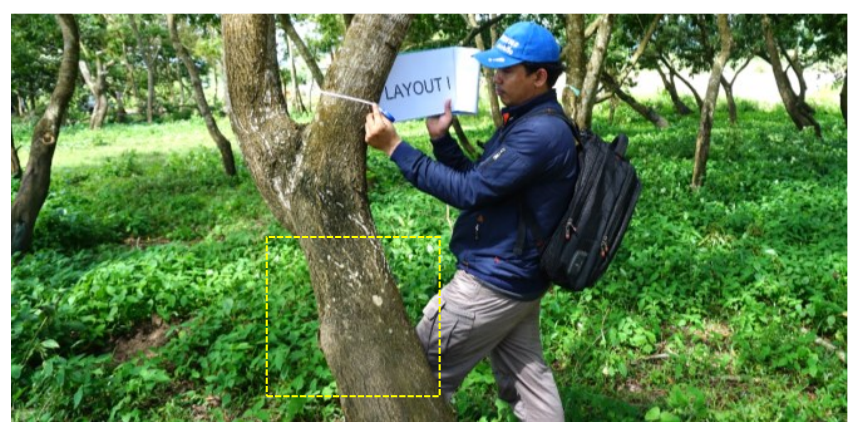

Figure 2. The structural portrait of a tree in Pacitan Bay

Significant differences between the two methods may be clearly seen when simulating a tsunami interaction with a solid building where the tsunami flow is lower than the seawall crest (Benazir et al., 2017). In Figure 3 it is shown that the total reflection process was accommodated by the CRRM method so that the wave returned to the sea and the absence of run-up in the downstream model, but the wave passed the model in the ERM method.

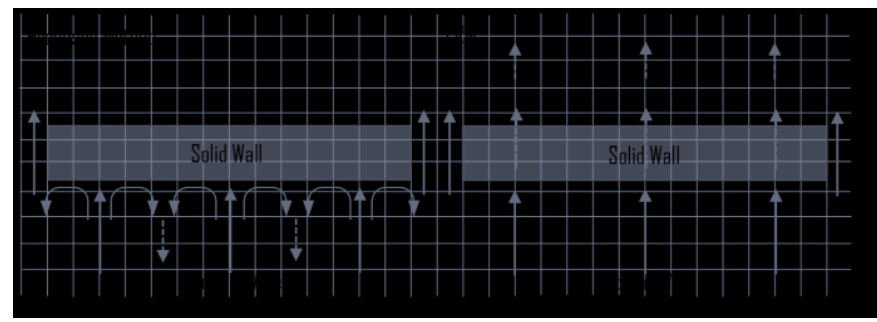

Figure 3. Both CRRM and ERM methods performance based on Benazir et al. (2017)

\subsection{Experimental Setup: Model Verification}

The simulation was performed in a flume of dimensions $15.00 \mathrm{~m} \times 0.60 \mathrm{~m} \times 0.44 \mathrm{~m}$. This is aimed at validating the numerical model. The flume was available at the Hydraulics-Hydrology Laboratory of the Center of Engineering Science, Universitas Gadjah Mada. The flume was divided into two regions, upstream of $4 \mathrm{~m}$ as a tsunami source and the downstream of $11 \mathrm{~m}$ as the investigation area (Figure 4). At the downstream, there was a constant depth of 3 $\mathrm{m}$ from the generation site, which was $0.10 \mathrm{~m}$ deep and followed by a constant bottom slope of 1:20 (vertical to horizontal) of $8 \mathrm{~m}$ long. Thus, the tsunami source was located $5 \mathrm{~m}$ from the coastline. 


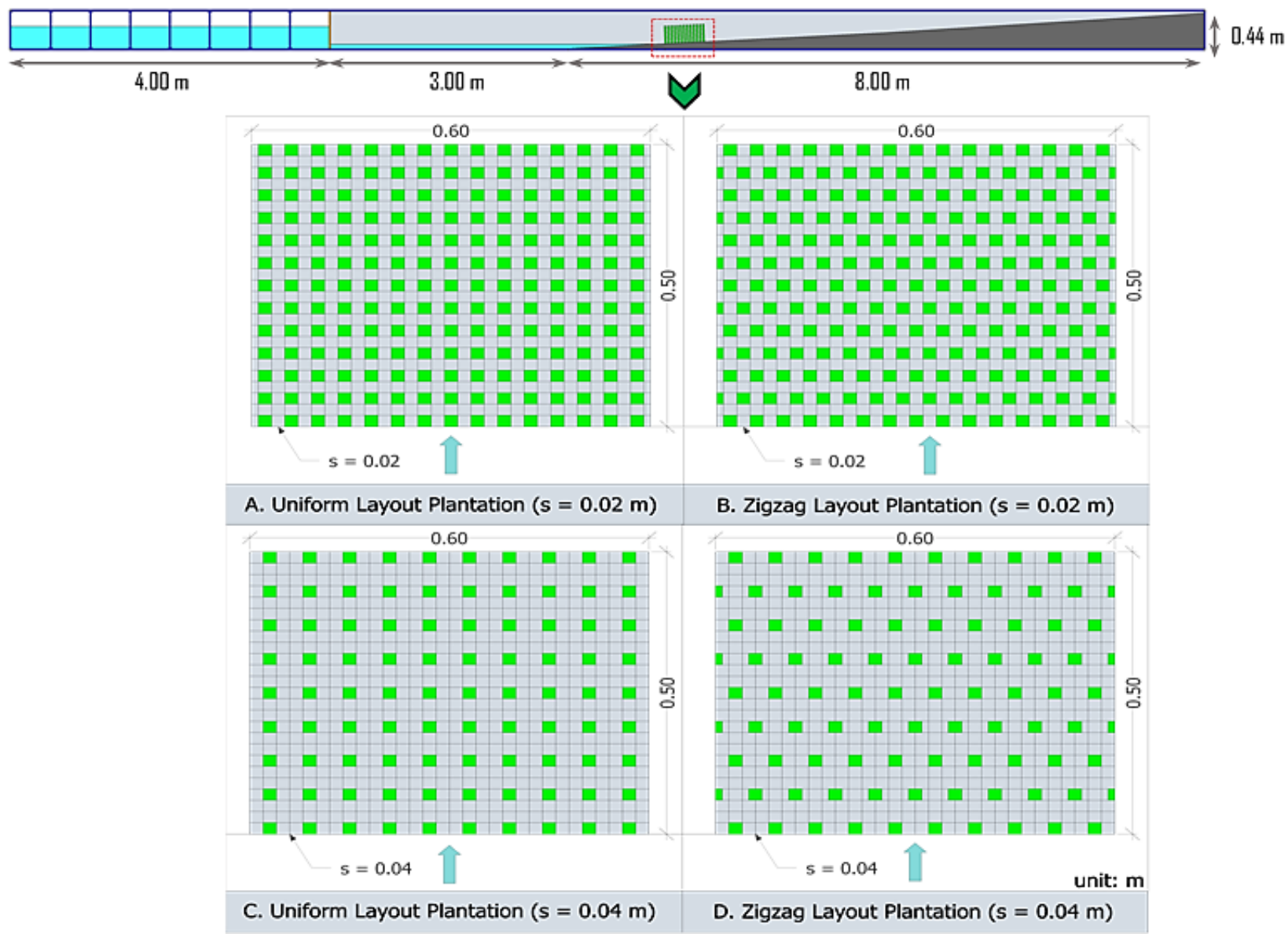

Figure 4. Domain simulation on the flume and the arrangement of uniform and zigzag layout models with variation of spacing between stem $(s)$

The arrangement of the vegetation model was either uniform or zigzag as shown in Figure 4. The design concept of CRRM method is that the overall parameters in a tree such as stems, branches, and leaves are represented by a square column model (Figure 4 ). The dimensions of this model were $0.02 \mathrm{~m} \times 0.02 \mathrm{~m}$ with the model height was adjusted to the tsunami simulation scenario so that the trees elevation was higher than the tsunami even after the reflection so that no overtopping occurs. The arrangement of the uniform model was commonly found in the coastal forest. The density of this forest model depended on the ratio of the total area of trees to the area of coastal forest, i.e. 195 trees for interval distance, $s=0.02 \mathrm{~m}$ (25\% density) and 90 trees for $s=0.04 \mathrm{~m}(11 \%$ density). The vegetation model was placed $0.10 \mathrm{~m}$ away from the coastline or $5.10 \mathrm{~m}$ of the wave generation source. The tsunami was generated by the Dam Break method where the method was described in Benazir et al. (2018). The initial condition of tsunami was $d_{0} / d_{1}=$ 2.0 with $d_{1}=0.1 \mathrm{~m}$ as the downstream depth. The other parameters for this numerical model such as the grid numbers and grid size are shown in Table 1.
Table 1. The parameters that used for numerical computation

\begin{tabular}{|c|c|c|c|c|c|}
\hline \multicolumn{2}{|c|}{ Grid Numbers } & \multicolumn{2}{|c|}{ Grid Size $(\mathrm{m})$} & DT & Total Time \\
\hline $\mathrm{x}$ & $\mathrm{y}$ & $\mathrm{x}$ & $\mathrm{y}$ & $(\mathrm{s})$ & $(\mathrm{s})$ \\
\hline \hline 1500 & 60 & 0.01 & 0.01 & 0.0025 & 180 \\
\hline
\end{tabular}

For the purposes of model verification, a Hollow Galvalume type material, which is a hollow steel pipe square-shaped and made of galvalume or zincalume was chosen as the material of this model. This material was available in $6 \mathrm{~m}$ length and $0.02 \mathrm{~m} \times 0.02 \mathrm{~m}$ in cross section. The production process of this model is given in Figure 5.
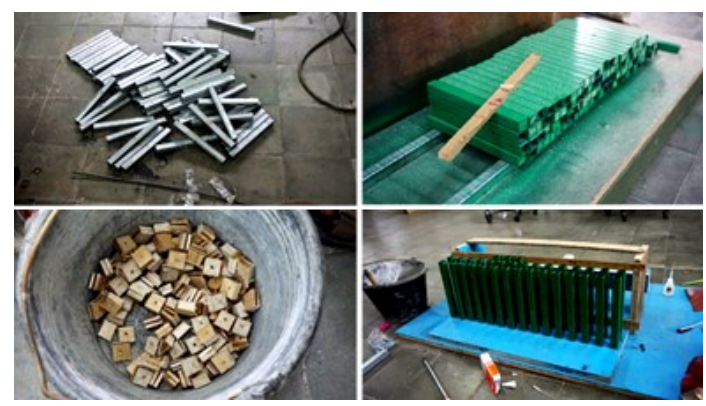

Figure 5. The production stage for the hypothetical model of coastal vegetation 
The model installation in the flume is shown in Figure 6 . The wave probes were positioned at $0.10 \mathrm{~m}$ upstream of the model and $0.10 \mathrm{~m}$ downstream of the model to record the wave reduction. In addition, two cameras were also placed in front and beside the models to record wave interaction with the vegetation model.

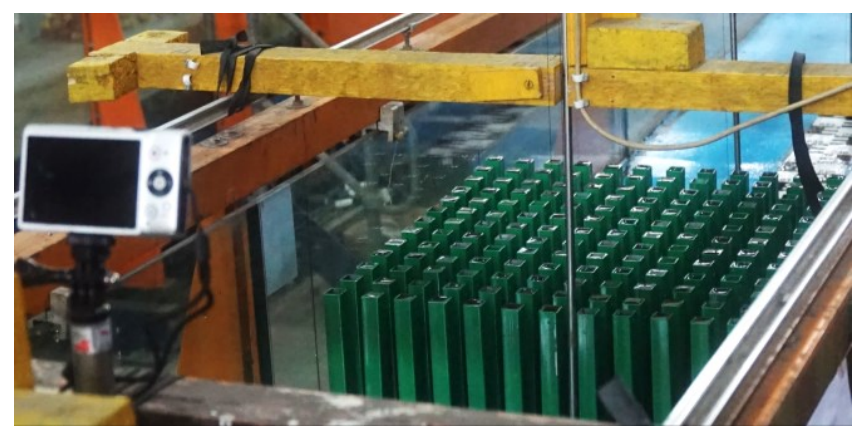

Figure 6. Installation of vegetation model for uniform arrangement type $(\boldsymbol{s}=0.02 \mathrm{~m})$

\section{RESULTS AND DISCUSSION}

\subsection{Benchmarking Model}

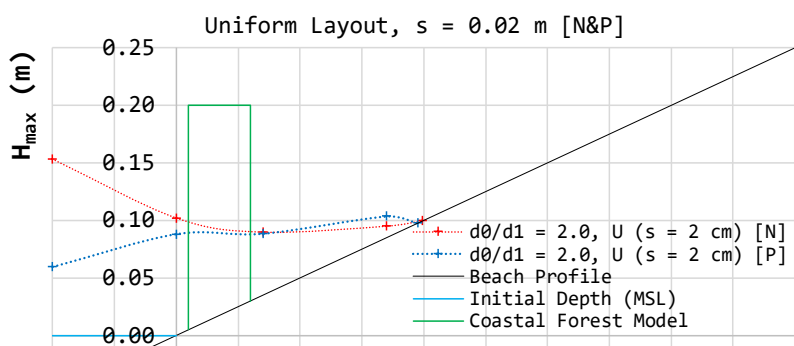

$-1.00-0.500 .000 .501 .001 .502 .002 .503 .003 .504 .004 .505 .00$ $-0.05$

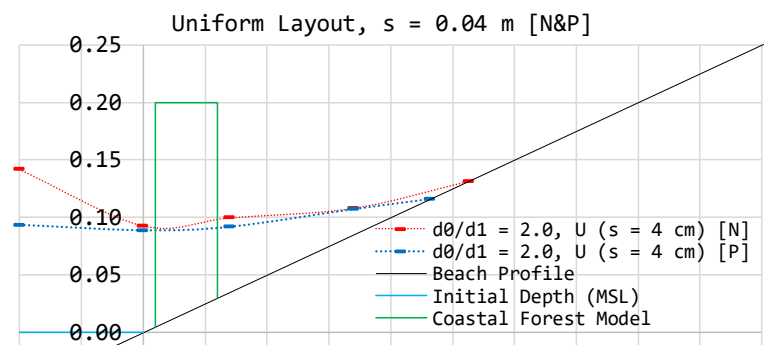

$-1.00-0.500 .000 .501 .001 .502 .002 .503 .003 .504 .004 .505 .00$ $-0.05$

$X_{i}(m)$

Figure 7. Comparison of physical and numerical model for CRRM method (uniform layout)

The verification results of the CRRM method using the physical model are shown in Figure 7 and 8. Higher run-up was produced by the numerical model when compared with the physical model results for uniform scenario (Figure 7). The deviations for this trees arrangement were $2.07 \%$ and $12.65 \%$ for $s=0.02 \mathrm{~m}$ and $s=0.04 \mathrm{~m}$, respectively. For zigzag model, the numerical run-up values were below the laboratory results. This condition was influenced by the grid size of the numerical model. The deviations for both models were in the range of $19.70 \%$ for $s=0.02 \mathrm{~m}$ and $19.60 \%$ for $s=0.04 \mathrm{~m}$. However, based on Synolakis et al. (2007), benchmarking of numerical model results with laboratory data should not exceed $20 \%$. Thus, it can be said that the results of the numerical model are acceptable and that further discussion of the results can be made.

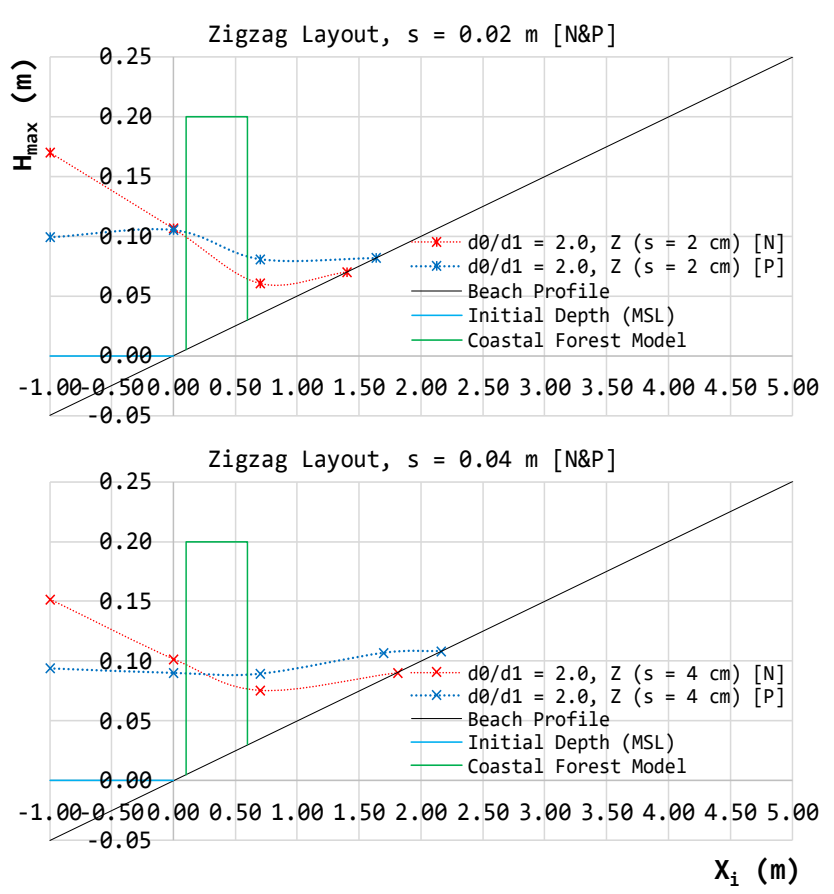

Figure 8. Comparison of physical and numerical model for CRRM method (zigzag arrangement)

\subsection{The Effect of Layout Plantation and Vegetation Density}

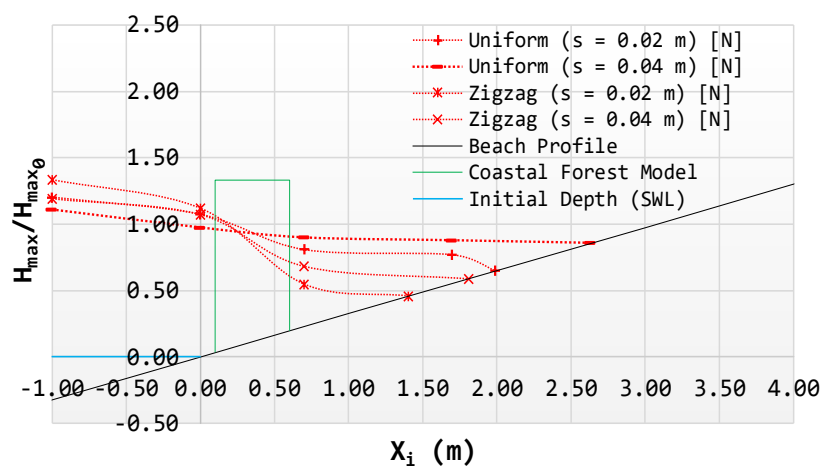

Figure 9. Distribution of maximum tsunami height near the coastline

Figure 9 shows the tsunami water level at maximum run-up at different layout (planting pattern) of coastal forests. In order to examine the effect of the layout, two different layouts were tested i.e. uniform and zigzag at constant $s$ size. The zigzag layout yields lower tsunami run-ups than the uniform layout. The reflection due to the trees plays more important role than the friction between the water and the surface trunk of the tree. 
Moreover, as the tsunami inundation decreased at the downstream of coastal forest, both the velocity and the energy reduced.

In Figure 9 it is also seen that the wave height in front of the model varies due to different forest model. The wave height at this point of measurement has been affected by wave reflection from the forest model so that the maximum flow depth is higher. The uniform forest layout arrangement with $\mathrm{s}=0.04 \mathrm{~m}$ produced a lower backwater compared to another arrangement of forest layout models. Higher backwater due to reflection process happened when the wave passes through a zigzag model with $s=0.02 \mathrm{~m}$. The forest density also plays a role of reflection process as shown in Figure 10. The figure shows the waves arrive at the coastline or $0.10 \mathrm{~m}$ in front of the model at $t=2.15 \mathrm{~s}$, after which the reflection occurred $(t=2.98 \mathrm{~s})$. The backwater process was shown at $t=3.80 \mathrm{~s}$ where the flow depth in front of the model became higher whilst the wave height reduced at downstream of the model. At $t=14.02 \mathrm{~s}$, the same Figure 10 showed the rundown process passing through the gaps between the trees.

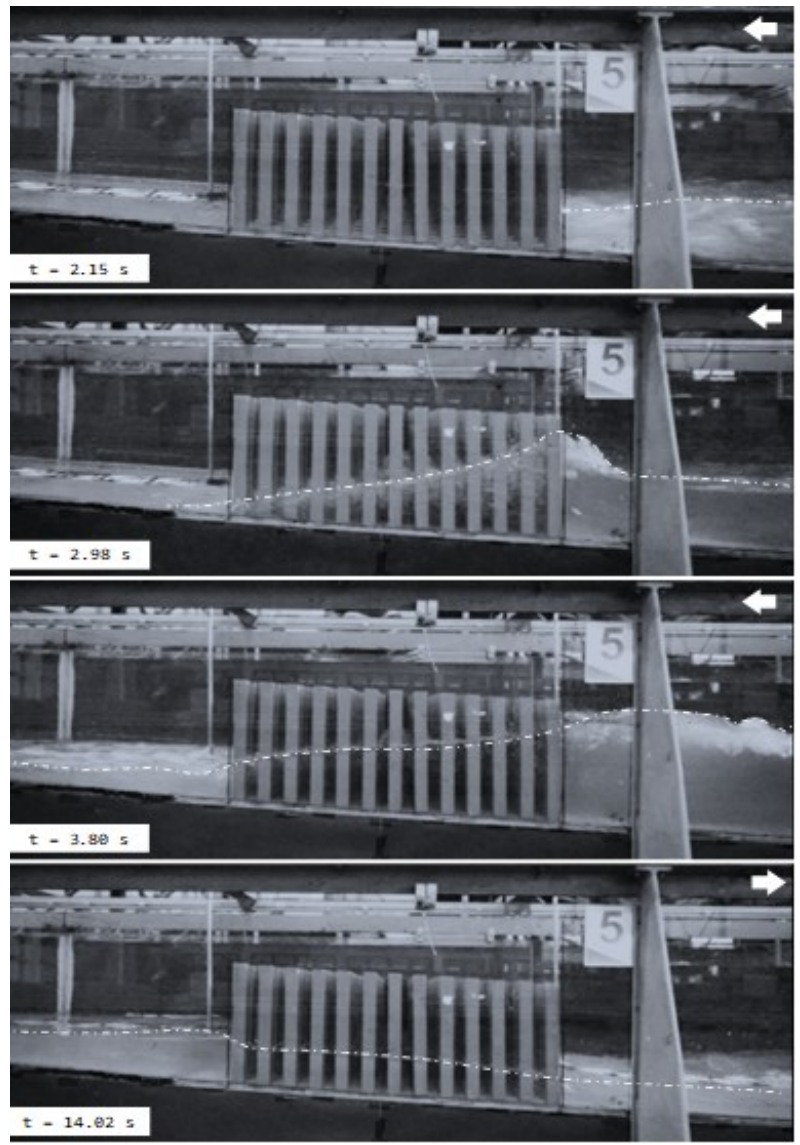

Figure 10. The wave reflection process that generates the backwater in front of the model on laboratory testing for a uniform model $(s=0.02 \mathrm{~m})$
To examine the effectiveness of the forest density in reducing tsunami run-up, a dimensionless parameter $H_{\max -d 0} / H_{\max 0}$ that represents the ratio between the maximum tsunami height with and without forest model, are shown in Figure 11. In this case $H_{\max -d 0} / H_{\max 0}$ was measured at $0.10 \mathrm{~m}$ downstream of the forest model. In the figure, the parameter $A_{c} / A_{a}$ is the relative area of the trees to the total area of the vegetation model. The results indicate that when $A_{c} / A_{a}$ increases, $H_{\max -d 0} / H_{\max 0}$ decreases. This means that higher density of a vegetation is more effective in reducing tsunami height downstream of the forest. The tsunami reduction became more significant when the forest model was arranged in zigzag manner for relatively large value of $A_{c} / A_{a}$.

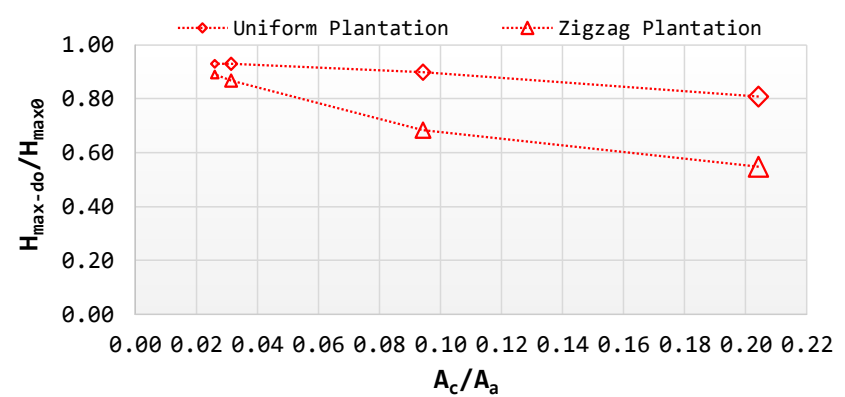

Figure 11. The effect of density variation over the maximum tsunami height behind the forest model (the higher density is indicated by larger symbols)

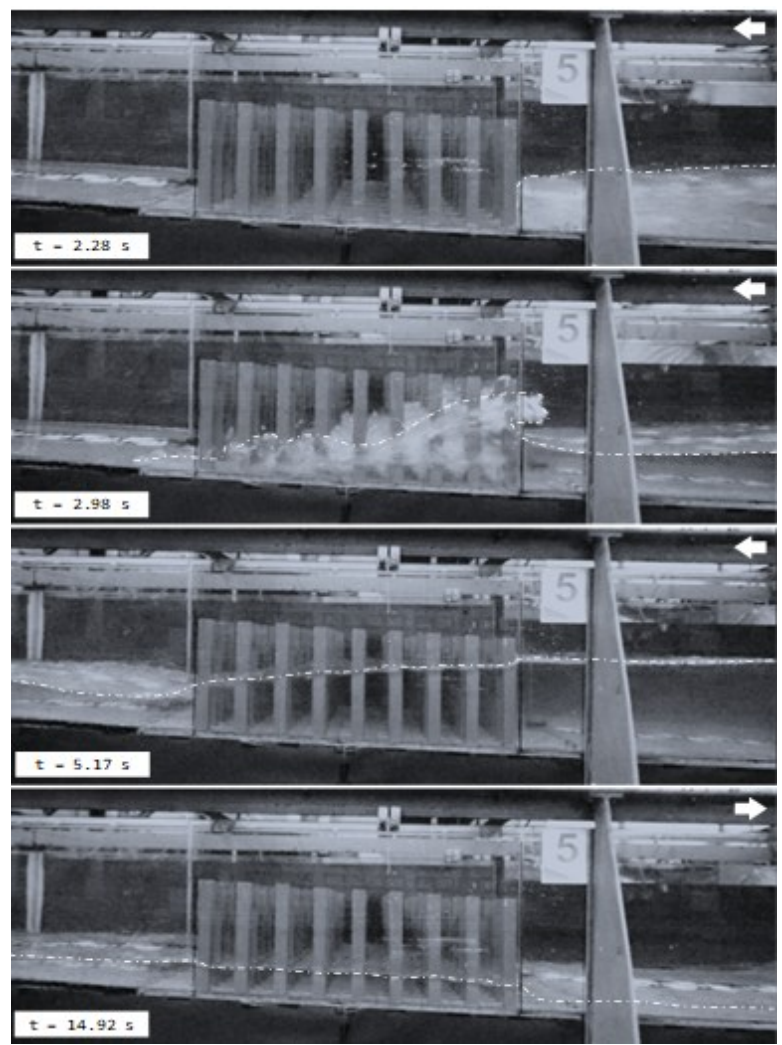

Figure 12. The wave reduction in front of the uniform model $(s=0.04 \mathrm{~m})$ 
Figure 12 shows the effect of uniformly arranged coastal forest with $s=0.04$. It may be concluded that the uniform arrangement with large space between the trees provides less significant effect on tsunami reduction.

\subsection{Run-up and Inundation}
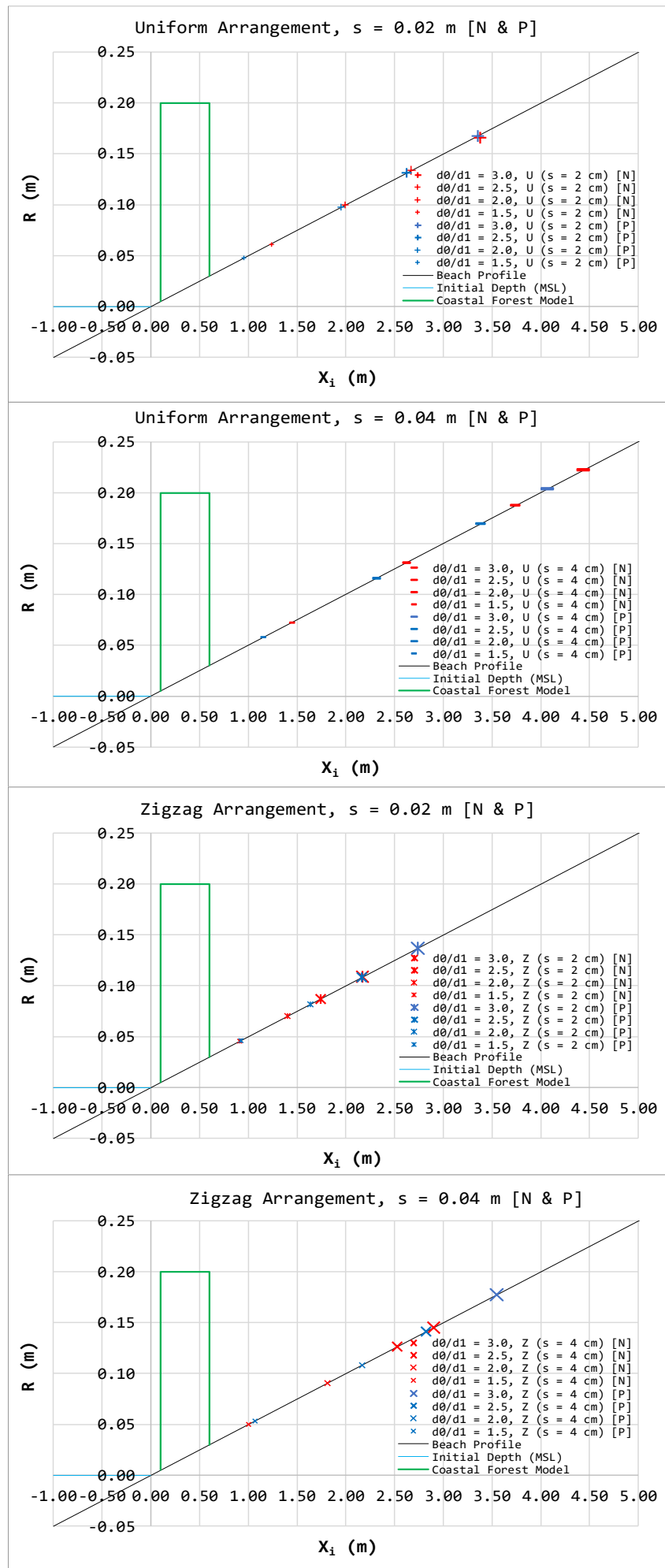

Figure 13. The relation of run-up and inundation for both numerical and physical models. Higher tsunami height is indicated by larger symbols
To further discuss the performance of the proposed method, a comparison of run-up $(R)$ and inundation $\left(X_{i}\right)$ resulted from laboratory data are presented in Figure 13. The figure shows that the smaller $s$ or high forest density yielded the smaller tsunami run-up for both uniform and zigzag arrangements where most of the energy is reflected by the forest. Very small deviations occurred for cases of uniform arrangement of both methods, especially for $s=0.02$. However, the numerical data for this arrangement were larger than the laboratory results which was consistent for the entire tsunami levels. This condition was due to the application of Shallow Water Equation in the numerical model where the energy reduction due to breaking wave was not implemented (see Benazir et al. 2018).

In the case of the zigzag arrangement, the higher runup data were produced by physical model. This could have been caused by the grid size of the numerical model as previously stated. Smaller grid sizes may reduce numerical dissipation where the flow may numerically more easily flow through the zigzag model and produce slightly higher run-up.

\section{CONCLUSIONS}

The success rate of a coastal vegetation for tsunami mitigation may not only be determined by the tsunamiscale, forest width, tree density, tree age, stem diameter, stem height, and species of the tree but also the layout of tree plantation. Based on the results of both physical and numerical models, the zigzag layout was better in reducing tsunami run-up compared to the usual (uniform) tree planting arrangement.

The Combined Roughness and Reflected Model (CRRM), was capable to obtain sufficiently accurate run-up data as verified by the physical model. This CRRM method was able to accommodate the physical wave reflection process when interacted with trees.

\section{ACKNOWLEDGMENTS}

The research was fully funded by Lembaga Pengelolaan Dana Pendidikan (LPDP) Ministry of Finance of the Republic of Indonesia via Scholarship of Indonesia Education (BPI). We would like to express our sincere gratitude for the funding.

\section{REFERENCES}

Benazir, Triatmadja, R., Rahardjo, A. P. \& Yuwono, N., 2016. Studi Interaksi Gelombang Tsunami terhadap Struktur Mitigasi dan Pengaruhnya dalam Pembentukan Run-Up di Daratan Pantai. Semarang, Pertemuan Ilmiah Tahunan (PIT) HATHI XXXIII, 2527 November, pp. 525-534. 
Benazir, Triatmadja, R., Rahardjo, A. P. \& Yuwono, N., 2017. Comparison of Methods for Simulating Tsunami Run-up Through Coastal Forests. Science of Tsunami Hazards, 36(3), pp. 167-182.

Benazir, Triatmadja, R., Rahardjo, A. P. \& Yuwono, N., 2018. The Behavior of Tsunami-like Waveform using Dam Break Method and Its Run-up on 1:20 Gradual Slope. Science of Tsunami Hazards (under review).

Chow, V. T., 1959. Open Channel Hydraulics. New York: McGraw-Hill.

Dahdough-Guebas, F. et al., 2005. How Effective were Mangroves as a Defence against the Recent Tsunami. Current Biology, 15(12), pp. R443-447.

Danielsen, F. et al., 2005. The Asian Tsunami: A Protective Role for Coastal Vegetation. Science, 310, p. 643.

EJF, 2006. Mangroves: Nature's Defence against Tsunamis - A Report on the Impact of Mangrove Loss and Shrimp Farm Development on Coastal Defences, London, UK: Environmental Justice Foundation.

Fernando, H. J. S. et al., 2008. Effects of Porous Barriers such as Coral Reefs on Coastal Wave Propagation. Hydro-environment Research, 1, pp. 187194.

Forbes, K. \& Broadhead, J., 2007. The Role of Coastal Forest in the Mitigation of Tsunami Impact. Bangkok: Food and Agriculture Organization of the United Nations.

Goto, C., Ogawa, Y., Shuto, N. \& Imamura, F., 1997. Numerical Method of Tsunami Simulation with LeapFrog Scheme, IOC Manual: IUGG/IOC Time Project, UNESCO.

Harada, K. \& Imamura, F., 2005. Effects of Coastal Forest on tsunami Hazard Mitigation - A Preliminary Investigation. In: Tsunamis, Case Studies and Recent Developments. Netherland: Springer, pp. 279-292.

Harada, K. \& Kawata, Y., 2004. Study on the Effect of Coastal Forest to Tsunami Reduction. Annuals of Disas. Prev. Res. Inst., Kyoto Univ., Issue 47 C.

Harada, K. \& Kawata, Y., 2005. Study on Tsunami Reduction Effect of Coastal Forest due to Forest Growth. Annuals of Disaster Prevention Research Institute, Kyoto Universty, Issue 48C.

Hiraishi, T. \& Harada, K., 2003. Greenbelt Tsunami Prevention in South-Pacific Region. Report of the Port and Airport Research Institute, 42(2).

Huang, Z., Yao, Y., Sim, S. Y. \& Yao, Y., 2011. Interaction od Solitary Waves with Emergent, Rigid Vegetation. Ocean Engineering, 38, pp. 1080-1088.
Husrin, S. \& Oumeraci, H., 2009. Parameterization of Coastal Forest Vegetation and Hydraulic Resistance Coefficients for Tsunami Modelling. Banda Aceh, 4th Annual International Workshop \& Expo on Sumatra Tsunami Disaster \& Recovery 2009.

Iimura, K. \& Tanaka, N., 2012. Numerical Simulation Estimating Effects of Tree Density Distribution in Coastal Forest on Tsunami Mitigation. Ocean Engineering, 54, pp. 223-232.

Imamura, F., Yalciner, A. C. \& Ozyurt, G., 2006. Tsunami Modelling Manual (TUNAMI Model). Sendai: Disaster Control Research Center, Tohoku University.

Irtem, E., Gedik, N., Kabdasli, M. S. \& Yasa, N. E., 2009. Coastal Forest Effects on Tsunami Run-up Heights. Ocean Engineering, 36, pp. 313-320.

Kathiresan, K. \& Rajendran, N., 2005. Coastal Mangrove Forests Mitigated Tsunami. Estuarine, Coastal and Shelf Science, 65, pp. 601-606.

Maza, M., Lara, J. L. \& Losada, I. J., 2015. Tsunami Wave Interaction with Mangrove Forest; a 3-D Numerical Approach. Coastal Engineering, 98, pp. 3354.

Mazda, Y., Magi, M., Kogo, M. \& Hong, P. N., 1997. Mangroves as a Coastal Protection from Waves in the Tong King Delta, Vietnam. Mangroves and Salt Marshes, 1, pp. 127-135.

Ohira, W., Honda, K. \& Harada, K., 2012. Reduction of Tsunami Inundation by Coastal Forests in Yogyakarta, Indonesia: a Numerical Study. Natural Hazards and Earth System Sciences, 12, pp. 85-95.

Shuto, N., 1987. The Effectiveness and Limit of Tsunami Control Forests. Coastal Engineering in Japan, 30, pp. 143-153.

Synolakis, C. E. et al., 2007. Standards, Criteria, and Procedures for NOAA Evaluation of Tsunami Numerical Models, Washington: NOAA OAR Special Report-NOAA Technical Memorandum OAR PMEL135.

Teh, S. Y. et al., 2009. Analytical and Numerical Simulation of Tsunami Mitigation by Mangrove in Penang, Malaysia. Journal o Asian Earth Sciences, 36, pp. 38-46.

Thuy, N. B., Tanimoto, K., Tanaka, N. \& Iimura, K., 2009. Effect of Open Gap in Coastal Forest on Tsunami Run-up-Investigations by Experiment and Numerical Simulation. Ocean Engineering, 36, pp. 1258-1269. 